was estimated using a generalised estimating equation extension of multivariate Poisson regression models.

Results: We identified 81568 incident cases of PsO/PsA (mean age 48.5 years [SD 17.8], 51.5\% female). Individuals with PsO/PsA were at significantly higher risk of being diagnosed with 8/41 types of cancer examined, including eye and orbit (4 fold), female genital ( 3 fold), non-melanoma skin ( 2 fold), prostate (males; 1.1 fold) (table 1). Incidence of rectal and colon cancer was lower among $\mathrm{PsO} /$ PsA pts relative to the non-PsO/PsA cohort (table 1).

Abstract OP0130 - Table 1. Incidence Rate (IR) and Incidence Rate Ratio (IRR) of Cancer Among PsO/PsA Pts Compared With the General Population

\begin{tabular}{|c|c|c|c|c|c|c|c|}
\hline Outcome & $\begin{array}{c}\text { PsO/ } \\
\text { PsA } \\
\text { events }\end{array}$ & $\begin{array}{c}\text { Non- } \\
\text { PsO/ } \\
\text { PsA } \\
\text { events }\end{array}$ & $\begin{array}{l}\mathrm{PsO} / \mathrm{PsA} \\
\text { follow-up } \\
\text { (PY) }\end{array}$ & $\begin{array}{l}\text { Non-PsO/ } \\
\text { PsA } \\
\text { follow-up } \\
\text { (PY) }\end{array}$ & $\begin{array}{c}\text { PsO/ } \\
\text { PsA IR } \\
\text { (per } \\
100,000 \\
\text { PY) }\end{array}$ & $\begin{array}{c}\text { Non- } \\
\text { PsO/ } \\
\text { PsA IR } \\
\text { (per } \\
100,000 \\
\text { PY) }\end{array}$ & $\begin{array}{c}\text { IRR } \\
(95 \% \mathrm{Cl})\end{array}$ \\
\hline $\begin{array}{l}\text { Eye and } \\
\text { orbit }\end{array}$ & 13 & $<5$ & $623,843.5$ & $<5$ & 2.08 & - & $\begin{array}{c}4.25 \\
(1.21- \\
14.91)\end{array}$ \\
\hline $\begin{array}{l}\text { Female } \\
\text { genital } \\
\text { other than } \\
\text { cervix } \\
\text { uteri, } \\
\text { corpus } \\
\text { uteri and } \\
\text { ovary }\end{array}$ & 55 & 21 & $623,625.8$ & $611,542.1$ & 8.81 & 3.43 & $\begin{array}{c}2.57 \\
(1.55- \\
4.25)\end{array}$ \\
\hline $\begin{array}{l}\text { Other } \\
\text { urinary }\end{array}$ & 31 & 16 & $623,818.6$ & $611,585.4$ & 4.97 & 2.62 & $\begin{array}{c}1.90 \\
(1.04- \\
3.47)\end{array}$ \\
\hline $\begin{array}{l}\text { Non- } \\
\text { melanoma } \\
\text { skin }\end{array}$ & 401 & 217 & $621,233.8$ & $610,223.9$ & 64.54 & 35.56 & $\begin{array}{c}1.82 \\
(1.54- \\
2.14)\end{array}$ \\
\hline Lung & 705 & 589 & $622,877.2$ & $610,834.8$ & 113.18 & 96.42 & $\begin{array}{c}1.17 \\
(1.05- \\
1.31)\end{array}$ \\
\hline Prostate & 760 & 664 & $620,065.8$ & $608,124.9$ & 122.57 & 109.19 & $\begin{array}{c}1.12 \\
(1.01- \\
1.25)\end{array}$ \\
\hline Melanoma & 218 & 200 & 622791 & $610,672.1$ & 35.00 & 32.75 & $\begin{array}{c}1.07 \\
(0.88- \\
1.29)\end{array}$ \\
\hline Colon & 286 & 332 & $622,845.1$ & $610,410.5$ & 45.91 & 54.39 & $\begin{array}{c}0.84 \\
(0.72- \\
0.99)\end{array}$ \\
\hline Rectum & 157 & 194 & $623,196.9$ & $610,811.7$ & 25.19 & 31.76 & $\begin{array}{c}0.79 \\
(0.64- \\
0.98) \\
\end{array}$ \\
\hline
\end{tabular}

PY=patient years

Conclusions: This general population-based study demonstrates that pts with $\mathrm{PsO} / \mathrm{PsA}$ have an increased risk of several types of cancer, and a decreased risk of rectal and colon cancer. This association highlights the need to further explore potential risk factors and pathways that contribute to these complications.

Acknowledgements: This study received an unrestricted grant from BristolMyers Squibb for an investigator-initiated project in $\mathrm{PsO} / \mathrm{PsA}$

Disclosure of Interest: J. A. Avina-Zubieta Grant/research support from: BristolMyers Squibb, A. Dominique Employee of: Bristol-Myers Squibb, T. Simon Employee of: Bristol-Myers Squibb, H. Tavakoli Grant/research support from: Bristol-Myers Squibb

DOI: 10.1136/annrheumdis-2018-eular.3772

\section{OP0131 INNATE LYMPHOID CELLS CORRELATE WITH DISEASE ACTIVITY AND BONE REMODELLING IN PSORIATIC ARTHRITIS}

A. Soare ${ }^{1}$, S. Weber ${ }^{1}$, L. Maul ${ }^{1}$, S. Rauber ${ }^{1}$, A.M. Gheorghiu ${ }^{2}$, I. Houssni ${ }^{1}$, A. Kleyer ${ }^{1}$, M. Luber ${ }^{1}$, J. Rech ${ }^{1}$, G. Schett ${ }^{1}$, J. Distler ${ }^{1}$, A. Ramming ${ }^{1} .{ }^{1}$ Department of Internal Medicine 3, Rheumatology and Immunology, Friedrich-AlexanderUniversity (FAU) Erlangen-Nürnberg, Erlangen, Germany, ${ }^{2}$ Dr. I. Cantacuzino Clinical Hospital, Carol Davila University of Medicine and Pharmacy, Bucharest, Romania

Background: Evaluation of actual immunopathology in psoriatic arthritis (PsA) is challenging. Current composite measures approved for PsA are very useful tools to assess disease activity in clinical routine. Nonetheless, because of subjective patients' estimations that widely affect the scoring, in particular the distinction between remission and low disease activity is a common question of debate.
Innate lymphoid cells (ILC) subsets may couple different aspects of PsA disease activity.

Objectives: To address whether PsA is associated with an altered composition of innate lymphoid cells and whether such changes are associated with disease activity and structural damage in PsA.

Methods: 124 patients satisfying the Classification Criteria for Psoriatic Arthritis (CASPAR) and 26 healthy volunteers were enrolled in the study. Information regarding clinical features, laboratory parameters were collected and disease activity score 28 (DAS28), disease activity in psoriatic arthritis (DAPSA), minimal disease activity score (MDA) were calculated. MRI and high-resolution periphera CT were taken and PSA MRI score (PsAMRIS) was assessed. Flow cytometric analysis was performed and IFNg-producing ILC1s, IL-4/IL-5-producing ILC2s and IL-17/IL-22-producing ILC3s were identified among ILCs. Multivariate linea regression and Receiver-Operating Characteristic (ROC) Curve analysis was performed using the IBM SPSS Statistics software.

Results: Total number of circulating ILCs were increased in PsA patients compared to healthy controls $(p<0,001)$. Linear regression analyses of the relationship between disease activity and circulating ILC counts showed that ILC2 negatively and ILC1 and ILC3 positively correlated with DAPSA score. The strongest correlation was observed when the ratio of ILC2 to ILC3 was analysed $(R=-0.5709$ $\mathrm{p}<0.0001)$. ILC2/3 ratio was also reduced in patients with active psoriatic skin dis ease, presence of enthesitis or a history of concomitant uveitis. Extend of synovitis or tenosynovitis or presence of bone erosions or osteophytes on MRI was inversely correlated with the ILC2/3 ratio $(R=-0.6753 ; p<0.0001, R=-0.5828$; $\mathrm{p}=0.0011$ and $\mathrm{p}<0.001$ respectively). Consistently, presence of erosions and/or osteoproliferation assessed by HR-pQCT was correlated with a significant lower ILC2/3 ratio. Furthermore, ROC Curve was used to test the performance of the ILC2/3 ratio as marker in differentiating between remission and disease activity of PsA. Indeed, a cut-off 0.57 exhibited highest sensitivity (92.9\%) and a $84.7 \%$ specificity in identifying remission.

Conclusions: The ILC2/3 ratio correlates with various facets of PsA manifestations and might be a useful tool to evaluate disease activity in PsA patients.

Disclosure of Interest: None declared

DOI: 10.1136/annrheumdis-2018-eular.7177

\section{OP0132 STRUCTURAL AND MICROSTRUCTURAL INTRA- ARTICULAR BONE CHANGES AT THE METACARPAL HEADS IN PATIENTS WITH PSORIATIC ARTHRITIS COMPARED TO CONTROLS: A HR-PQCT STUDY}

D. Wu ${ }^{1}$, J.F. Griffith ${ }^{2}$, S.H. Lam ${ }^{1}$, P. Wong ${ }^{1}$, J. Yue ${ }^{1}$, L. Shi ${ }^{3}$, E.K. Li ${ }^{1}$, I.T. Cheng ${ }^{1}$, T.K. Li', T.Y. Zhu' ${ }^{4}$, V.W. Hung ${ }^{4}$, L. Qin ${ }^{4}$, L.-S. Tam ${ }^{1}{ }^{1}$ Department of Medicine and Therapeutics; ${ }^{2}$ Department of Imaging and Interventional Radiology; ${ }^{3}$ Research Center for Medical Image Computing, Department of Imaging and Interventional Radiology; ${ }^{4}$ Bone Quality and Health Center of the Department of Orthopedics and Traumatology, The Prince of Wales Hospital, The Chinese University of Hong Kong, Hong Kong, China

Background: Located inside the joint capsule ${ }^{1}$ the entire metacarpal head $(\mathrm{MCH})$ is directly exposed to intra-articular inflammatory milieu in patients with psoriatic arthritis (PsA). We hypothesise that bone loss and new bone formation in the $\mathrm{MCH}$ will be more prominent in PsA compared to healthy controls.

Objectives: To investigate structural (bone erosion and enthesiophyte) and microstructural intra-articular bone changes in patients with PsA at the second and third $\mathrm{MCH}(\mathrm{MCH} 2$ and 3$)$ compared with controls.

Methods: 139 subjects (77PsA, 62 control) underwent HR CT scanning at the $\mathrm{MCH} 2$ and 3 and distal radius. 15 patients with joint destruction ${ }^{2}$ were excluded from further analysis. An integrative CART-EBEE approach was developed to investigate the structural and microstructural bone changes. CART method $(A B)$ was used to calculate volume of bone erosion and enthesiophyte [Crop of metacarpal bone(a,b); Automated segmentation of periosteal surface (c,e);Restoration of the missing cortical boundary based on anatomic curve(d,f);Three-dimensiona calculation of volume(g)]; EBEE method was used to calculate volumetric bone mineral density (VBMD) and microstructure before and after exclusion of Bone Erosion (C) and Enthesiophyte (D).

Results: 62 patients with PsA and controls were comparable in age, gender and body mass index. PsA patients had a significantly increased number (mean $\pm S D$ patient $2.4 \pm 1.4$ vs $1.3 \pm 1.1, p<0.001)$ and total volume of enthesiophytes $(8.75$ \pm 6.92 vs $4.36 \pm 4.90 \mathrm{~mm}^{3}, \mathrm{p}<0.001$ ); but a similar number of bone erosion (mean $\pm \mathrm{SD} /$ patient $2.9 \pm 1.2$ vs $2.7 \pm 1.4, \mathrm{p}=0.408$ ) and a trend suggestive of an increase in total volume of bone erosion $\left(11.88 \pm 7.82\right.$ vs $9.64 \pm 5.96 \mathrm{~mm}^{3}$ $\mathrm{p}=0.076$ ) per person compared with control. Depth of each individual bone erosion was greater in PSA than control; while no differences in the maximal height of each individual enthesiophyte was found between PsA and control. With regards to the microstructure, PsA showed a significantly decreased total vBMD, cortical vBMD (Ct.vBMD) and Ct. thickness at the distal radius; while a preferential bone loss at the trabecular (Tb.) compartment [Tb. vBMD; trabecular bone volume 